\title{
Circadian Activity Patterns and Time Budgets of the Complex-Toothed Flying Squirrel (Trogopterus xanthipes) in Different Seasons
}

\author{
Zhi Wang ${ }^{*}$, Wenhua Liu ${ }^{2}$ and FadaoTai ${ }^{3}$ \\ ${ }^{1}$ College of Life Sciences and Food Engineering, Shaanxi Xueqian Normal University, \\ Xi'an 710100, China \\ ${ }^{2}$ Shaanxi Institute of Zoology, Xi'an 710032, China. \\ ${ }^{3}$ College of Life Sciences, Shaanxi Normal University, Xi'an 710119, China.
}

\begin{abstract}
A B S T R A C T
The complex-toothed flying squirrel has completely different diet and living habits compared with other squirrel species. Still, its circadian activity patterns and time budgets in different behaviors remain unclear. Using artificial population of the animal bred in a simulated natural environment, activity patterns and time budgets were investigated. The results showed that the species was clearly nocturnal but varied greatly in the number of daily activity bouts showing bimodal patterns in winter, trimodal patterns in spring and summer, even tetramodal patterns in autumn. It is possible that they are the most active in autumn and they reduce activity times per bout in winter to reduce energy loss arising from prolonged exposure to cold temperatures, as a survival strategy. Squirrels were observed for a total of $1680 \mathrm{~h}$, they devoted $65.71 \% \pm 1.64$ of time to resting. Feeding accounted for $16.82 \% \pm 0.64$ of observation time. Other behaviors included self-grooming, watching, locomotion and so on. The percentages of nighttime spent in each of all behaviors varied greatly in some time period among different seasons, especially near early evening and midnight. This may be ascribed to variation in photoperiod.
\end{abstract}

Article Information
Received 23 March 2020
Revised 30 May 2020
Accepted 10 November 2020
Available online 28 June 2021
Authors' Contribution
WZ contributed to the conception of
the study, performed the experiment
and wrote the manuscript. LW
performed the data analyses. TF
helped perform the analysis with
constructive discussions.
Key words
Circadian activity pattern, Time
budget, The complex-toothed flying
squirrel, Behavior, Diet

\section{INTRODUCTION}

A nimals on the earth develop the ability to predict the day-night cycle and generally show oscillations in their behavioral repertoire throughout the day on specific time of the year (besides other time scales) to adjust to variations in environmental and climatic conditions (Alcock, 2005; Prendergast et al., 2002). Rhythmic phenomena that display daily oscillations in mammals include locomotor activity patterns, body temperature patterns and so on (Reiter, 1988; Jacob et al., 1997). This may also be expanded to show seasonal differences in activity as the photoperiod changes (Turek and Campbell, 1979). This rhythmic phenomena in animals may be generated by endogenous circadian clock and synchronized by light (Aschoff, 1960; Pittendrigh, 1960; Panda et al., 2002). Because different animals have different activities, feeding habits and reproduction circles in different environments, the circadian activity patterns and time budgets in different seasons may be species-specific. The Sciuridae show significant diversification in diet and some even develop as dietary specificity. For instance,

\footnotetext{
* Corresponding author: w.z014@163.com

0030-9923/2021/0005-1683 \$ 9.00/0

Copyright 2021 Zoological Society of Pakistan
}

the woolly flying squirrel (Eupetauras cinereus) from Pakistan, India, and Tibet, which fed mostly or entirely upon pine needles (Zahler and Khan, 2003). Some became extensive in diet, such as Ingram's squirrel (Guerlinguetus ingrami) from Brazil. The diet of it mainly contains fruits, seeds, but also flowers, tree bark, mushrooms, lichens, moss, bird eggs, leaves and insects (Ribeiro et al., 2009; Mendes and Cândido-Jr, 2014). Thus, circadian activity patterns and time budgets may show significant difference in the Sciuridae.

The complex-toothed flying squirrel (Trogopterus xanthipes) is an endemic in mountain belts of southwest and central China (Wang, 1985; Wang et al., 1987; Wang and $\mathrm{Xu}, 1992$; Smith and Xie, 2009). The species is medium-sized (300-500g) arboreal, gliding squirrel, inhabiting in mixed coniferous and broadleaf forests in the wild (Gao and Deng, 1983; Wang and Wang, 1995). Its nest was located in rock crevices or tree cavities. The animal feeds mainly upon leaves of Platycladus orientalis and Pinus tabuliformis, as well as branches, leaves and cones of Quercus. Its feces, called "Wulingzhi" after seasoning, has been used for traditional Chinese medicine to treat blood stasis and reduce pain for centuries $(\mathrm{Li}$, 1982). Pharmacological research showed that the crude extract of "Wulingzhi" possesses antitumor activity (Kosuge et al., 1985) and some chemical constituents 
with anticoagulation, enhancing immunity, and antiinflammation (Tang and Huang, 2008). In recent years, the animal has been bred artificially as an economic animal in China and its seasoned feces has been exported to Japan and South Korea as commodity with very high price. Because of great economic benefits, the species' population in the wild has been as vulnerable in the Chinese Red List (Wang, 1998) and near threatened in the IUCN Red List of Threatened Species (Johnston and Smith, 2016).

Previous studies regarding the animal mainly focused on its domestication, management and preliminary ecological research. For example, it is herbivorous with two-year sexual maturity and breeding period from January to April once per year (Wang et al., 1987; Wang and Wang, 1995; Liu and Li, 2000; Liu et al., 2001), relatively little is known about the circadian activity patterns and time budgets especially in different seasons. In addition, other behaviors (such as resting, feeding, etc) also remain unknown because of the animal's nocturnality and arboreality.

Knowledge of daily and seasonal activity patterns and time budgets is essential for evaluating foraging strategies of herbivores (Cederlund et al., 1989), and it can provide useful information (Duncan, 1985) because the activity patterns of the animal results from a complex compromise between optimal foraging time, social activities, environmental constraints and diets (Aschoff, 1963). The main diet of the animal are leaves which are significantly different from other squirrel species, while the latter mainly feed on fruits and nuts (Wang and Wang, 1995; Liu et al., 2001). Whether its activity patterns and time budgets are similar to other squirrel species remains unclear. Exploring of the knowledge can also provide helpful information for management of artificial breeding population of this species as it can be used to assign daily feeding time and other major activities in different seasons. The study may also provide important information for the conservation of this near threatened species.

\section{MATERIALS AND METHODS}

\section{Animals and housing}

Subjects were descendents of artificially breeding $T$. xanthipes populations originating from the east of Qinling Mountains in China. The breeding room is situated at $33^{\circ} 54^{\prime} \mathrm{N}$ latitude and $109^{\circ} 52^{\prime} \mathrm{E}$ longitude and about $935 \mathrm{~m}$ above sea level. These animals were singly housed in edgewooden cages measuring $50 \mathrm{~cm} \times 70 \mathrm{~cm} \times 72 \mathrm{~cm}$. In cages, a small wooden cell (W: $25 \mathrm{~cm}, \mathrm{H}: 25 \mathrm{~cm}, \mathrm{~L}: 25 \mathrm{~cm}$ ) with a circular hole (D: $7 \mathrm{~cm})$ was hung by thin iron wires as a nest box. Sixteen healthy adult animals (eight males, eight females, two years old, mean body mass, $379.48 \pm 84.56 \mathrm{~g}$ ) were used in our study. They were fed with leaves of Platycladus orientalis that were soaked by tap water for five to six $h$ once every day at 17:00-18:00. The cages were cleaned once a day and were kept with nearly natural LD cycles, a relative humidity of $70 \% \pm 20$ and a room temperature of $>-5^{\circ} \mathrm{C}$ in winter and $<32^{\circ} \mathrm{C}$ in summer.

\section{Behavioral observations}

Following a one-month preliminary observation, we found that almost all animals were only active at night, which was consistent with previous research (Wang et al., 1987; Wang and Wang, 1995). To record nightly activity, an infrared digital video recorder (HDR-PJ790E) (Japan, Sony China, co., LTD) was used in the absence of lamp lighting. For calculating the percentage of time budget for a particular behavior, quantitative behavioral data were collected in 5 consecutive days per month. The behavior state of the focal individual at each interval was recorded using focal animal sampling method. Based on these observations and previous studies on behavior categories of other animals in Sciuridae (Nunes et al., 2000; Holland et al., 2007; Essner, 2007; Youlatos and Samaras, 2011; Palmer and Koprowski, 2014; Mendes and Cândido-Jr, 2014), an ethogram was established as follow (see Table I for operational definition). For further analysis, the categories of locomotion, feeding, self-grooming, watching and other were classified as "activity". Approximately $1680 \mathrm{~h}$ of monitoring were conducted between August 2016 and July 2017.

Table I. Operational definition for behavior states recorded.

\begin{tabular}{|c|c|}
\hline Behavior & Definition \\
\hline Resting & $\begin{array}{l}\text { Lying in the cage or nest and sleeping, or } \\
\text { sitting still }\end{array}$ \\
\hline Feeding & $\begin{array}{l}\text { Engaging in behaviors related to searching } \\
\text { (smelling plants) for food, cutting chewing or } \\
\text { swallowing it }\end{array}$ \\
\hline Self-grooming & Licking its' body and adjusting itself in situ \\
\hline Watching & $\begin{array}{l}\text { The sight of the animal moving with the head } \\
\text { moving }\end{array}$ \\
\hline Locomotion & Walking without biting vegetation or leaping \\
\hline Other & $\begin{array}{l}\text { Behaviors not included in the above catego- } \\
\text { ries, mainly be out of sight or defecating or } \\
\text { biting the cage, etc. }\end{array}$ \\
\hline
\end{tabular}

\section{Statistical analysis}

The duration of all behaviors during the period of observation was scored and analyzed using $\mathrm{J}$ watcher v1.0 (http://www.jwatcher.ucla.edu/), which is a powerful 
tool for the quantitative analysis of behavior and can be used to address any theoretical problem that requires a complex sequence of actions to be scored by a human observer. For each observed individual, information is recorded on its activity state. All data were converted to percentage of total time spent on each type of behaviors and all means were calculated with standard error (SE). Because the behavioral data recorded were not normally distributed, nonparametric statistics were used for data analysis. Comparisons of time budgets among different seasons were performed using Kruskal-Wallis H test of non-parametric test. The Wilcoxon test was used to test the differences of the time budgets between males and females (Shi et al., 2003; Liu et al., 2005; Koprowski and Corse, 2005; Chen, 2010). All data were performed in IBM SPSS (version19) software, and significance was set at $P<0.05$.

\section{RESULTS}

Circadian activity patterns of the animals during one year

The activity patterns for T. xanthipes across $24 \mathrm{~h}$ of day and night among different seasons were presented in Figure 1. It is clear that the animals were active at night and resting during the day. They showed basically a tri modal activity pattern with a clear peak around dusk, midnight and dawn in spring and summer, separated by a rest period or decrease in activity. However, a quad modal activity pattern appeared in autumn and a bimodal activity pattern in winter. The percentage of activity was slightly different during each period among four seasons. The first peak occurred at 18:00-19:00 in autumn and winter while it was at 19:00-20:00 in spring and summer. The second peak appeared at 01:00-02:00 in spring, summer and winter (when the third peak in autumn arose). The second peak was at 22:00-23:00 in autumn when the activity of the animals approached to the lowest point of at night in spring, summer and winter. The third peak (for autumn, it was the fourth peak) in spring and summer was found at 03:00-04:00 and 04:00-05:00. Kruskal-Wallis tests showed that the percentage of activity at 17:00-21:00 and 23:00-01:00 varied significantly throughout day and night among seasons (Table II).

The nocturnal activity percentage of the animals among different months during one year was shown in Figure 2. The percentage of nocturnal activity across months did not show significant difference. The most striking characteristic was that fluctuations of the animals' mean percentage of activity had a smaller range from January to August and they arose their activity time to the tallest level $50.25 \% \pm 3.72$ in September. Then the activity percentage continued to fall until December when the nocturnal activity percentage reduced to the lowest level
$19.15 \% \pm 1.23$. However, the difference in percentage of nocturnal activity from January to December was not significant (Kruskal-Wallis test, $n=16, P>0.05$ ).

Table II. Comparison of the activity patterns of the animals across $h$ throughout day and night among seasons via Kruskal-Wallis $H$ test $(n=16)$ Data for the two sexes were pooled.

\begin{tabular}{lll}
\hline Time & \multicolumn{2}{c}{ Activity } \\
\cline { 2 - 3 } & \multicolumn{2}{c}{ P value } \\
\hline $0700-1700$ & - & - \\
$1700-1800$ & 8.946 & $0.030^{*}$ \\
$1800-1900$ & 10.579 & $0.014^{*}$ \\
$1900-2000$ & 9.991 & $0.019^{*}$ \\
$2000-2100$ & 15.191 & $0.002^{* *}$ \\
$2100-2200$ & 3.685 & 0.298 \\
$2200-2300$ & 6.815 & 0.078 \\
$2300-0000$ & 8.632 & $0.035^{*}$ \\
$0000-0100$ & 9.024 & $0.029^{*}$ \\
$0100-0200$ & 2.297 & 0.513 \\
$0200-0300$ & 3.582 & 0.310 \\
$0300-0400$ & 0.958 & 0.811 \\
$0400-0500$ & 1.389 & 0.708 \\
$0500-0600$ & 5.278 & 0.153 \\
$0600-0700$ & 5.915 & 0.116 \\
\hline
\end{tabular}

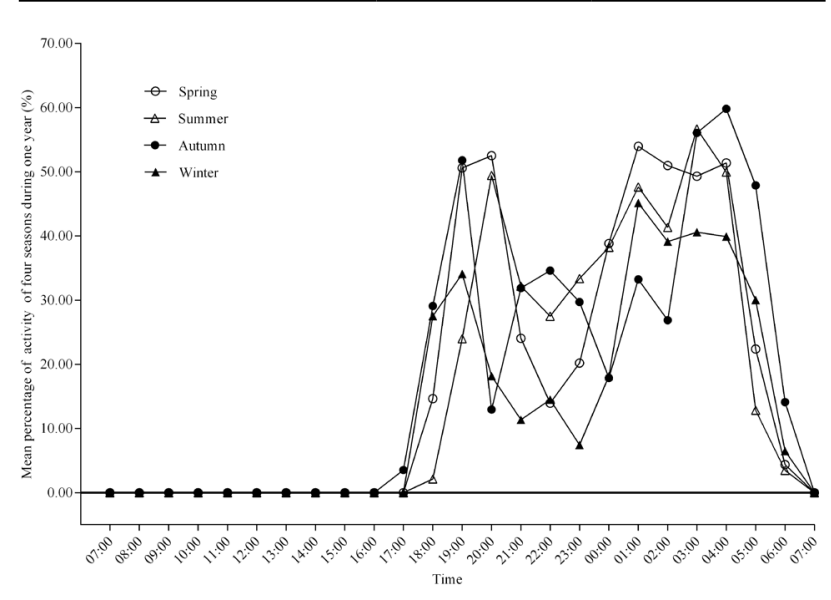

Fig. 1. Activity patterns profile for T. xanthipes among seasons during one year.

Seasonal variation in nocturnal time budgets of different behaviors during one year

The mean percentage of time for each behavior displayed by $T$. xanthipes across seasons during one year could be seen in Table III. No significant difference among 
seasons was found in time spent in resting, feeding, selfgrooming, locomotion, watching and other (KruskalWallis $\mathrm{H}$ test, $P>0.05, n=16$ ).

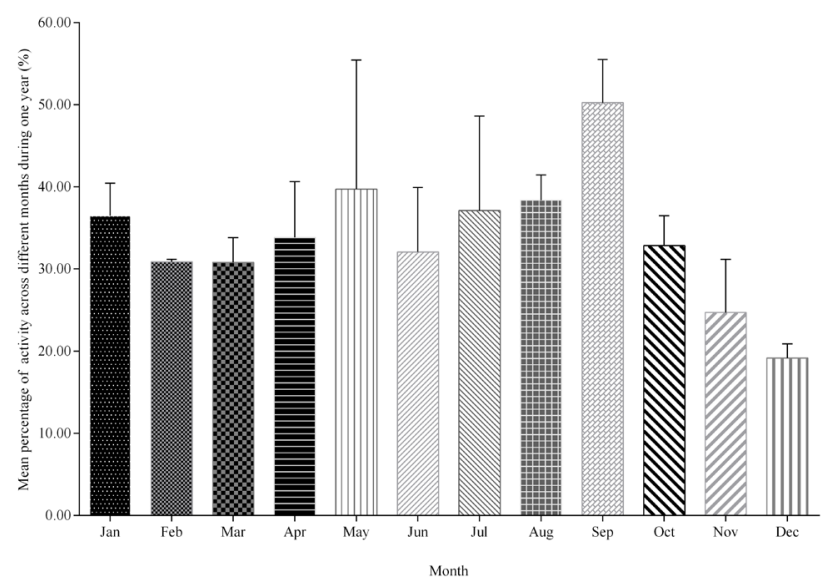

Fig. 2. The variation in percentage of nocturnal activity across months during one year. It was obtained by averaging corresponding data over the whole records.

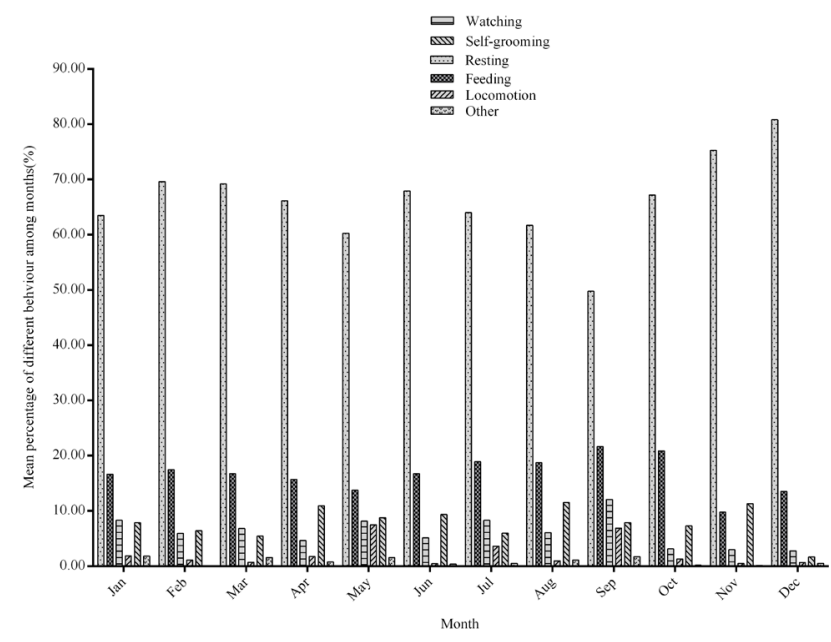

Fig. 3. Monthly nocturnal time budgets of different behaviors for T. xanthipes under cage condition.

\section{Monthly variation in time budgets of different behaviors during one year}

During one year, resting was the principal behavior of the animals and accounted for $65.71 \% \pm 1.64$ (Mean \pm SE). The second most frequent behavior observed was feeding, with a total of $16.82 \% \pm 0.64$ of the $h$. The remaining time was devoted to the other defined activities (including selfgrooming $8.25 \% \pm 0.67$, watching $6.25 \% \pm 0.60$, locomotion $2.35 \% \pm 0.73$, other $0.85 \% \pm 0.19$. The time budgets of different behaviors varied in different months (Fig. 3). The resting time was declined to the lowest level in September
$(49.75 \% \pm 3.72)$. The monthly variations in time spent in feeding were almost the reverse of the changes that of resting. The proportion of time devoted to feeding reached its highest level $(21.66 \% \pm 1.46)$ in September and it declined to the lowest level in December $(13.52 \% \pm 0.84)$.

\section{Sex difference in time budgets during one year}

During one year, time allocated to resting (Wilcoxon's signed-rank tests, $Z=-0.785, P=0.433)$, feeding $(Z=-0.804$, $P=0.421$ ), and the other behaviors did not show marked sexual variation (Table IV). However, it should be noted that there were some differences in the patterns of their monthly nocturnal time budgets, especially in resting and self-grooming (see Fig. 4). The valley of time resting in females appeared in May and September and the valley only existed in September in male. The time allocated to feeding behavior in both sexes was relatively balanced among months during one year, only there was a slight decrease in November. For male, the percentage of self-grooming behavior reached its maximum in August $(14.22 \% \pm$ 3.56 ), while the maximum was recorded in November for female $(16.05 \% \pm 4.28)$. It was worth mentioning that, the percentage of time spent in locomotion increased to the highest level in September in male $(10.92 \% \pm 2.34)$ while the highest level was remained in May in female $(21.57 \%$ $\pm 4.46)$. There were two separate peaks in May $(12.76 \% \pm$ $2.53)$ and September $(15.62 \% \pm 3.29)$ for the percentage of watching in female while it was relatively flat in male. The percentage of time in other behaviors remained relatively constant across months due to the smaller proportion in both sexes.

Diel variation in time budgets among different seasons

The time budgets across $\mathrm{h}$ of day and night among seasons were shown in Figure 5. During night in spring, resting only occurred a peak in 22:00-23:00. The pattern of variation in the percentage of time spent in feeding was nearly reciprocal to that of resting time. The animals showed an early morning (04:00-05:00) and an evening (19:00-20:00) peak of feeding in every season except summer. The peak of feeding in summer was at 20:0021:00 at night and 03:00-04:00 in the early morning. The self-grooming behavior appeared the first peak in early evening when feeding behavior occurred a peak, but the tendency of its percentage was not consistent with feeding behavior after midnight. The time in the significant differences in percentage of other activities (including watching, locomotion, other) among each time period was mainly in early evening. Kruskal-Wallis tests showed that the percentages of time spent in each of the seven defined behaviors vary significantly in some time (Table V). 
Table III. Mean percentage of different behaviors lasting for \pm standard error and Kruskal-Wallis $\mathrm{H}$ test results for focus animals among seasons during one year $(\alpha=0.05)$.

\begin{tabular}{llllll}
\hline Behavior state & Spring (\%) & Summer (\%) & Autumn (\%) & Winter (\%) & $\chi^{\mathbf{2}(\mathbf{P} \text {-value) }}$ \\
\hline Resting & $64.87 \pm 3.23$ & $64.24 \pm 2.33$ & $64.06 \pm 5.04$ & $71.32 \pm 3.31$ & $2.374(0.499)$ \\
Feeding & $15.29 \pm 0.55$ & $18.26 \pm 1.04$ & $17.44 \pm 2.49$ & $15.86 \pm 1.02$ & $5.287(0.152)$ \\
Self-grooming & $9.00 \pm 1.51$ & $8.91 \pm 0.93$ & $8.83 \pm 1.63$ & $5.31 \pm 1.24$ & $5.425(0.143)$ \\
Watching & $6.28 \pm 0.90$ & $6.63 \pm 1.03$ & $6.06 \pm 2.16$ & $5.68 \pm 1.20$ & $1.557(0.669)$ \\
Locomotion & $3.44 \pm 2.33$ & $1.79 \pm 0.78$ & $2.90 \pm 1.32$ & $1.21 \pm 0.33$ & $0.465(0.926)$ \\
Other & $1.30 \pm 0.26$ & $0.65 \pm 0.23$ & $0.70 \pm 0.52$ & $0.77 \pm 0.54$ & $1.531(0.675)$ \\
\hline
\end{tabular}

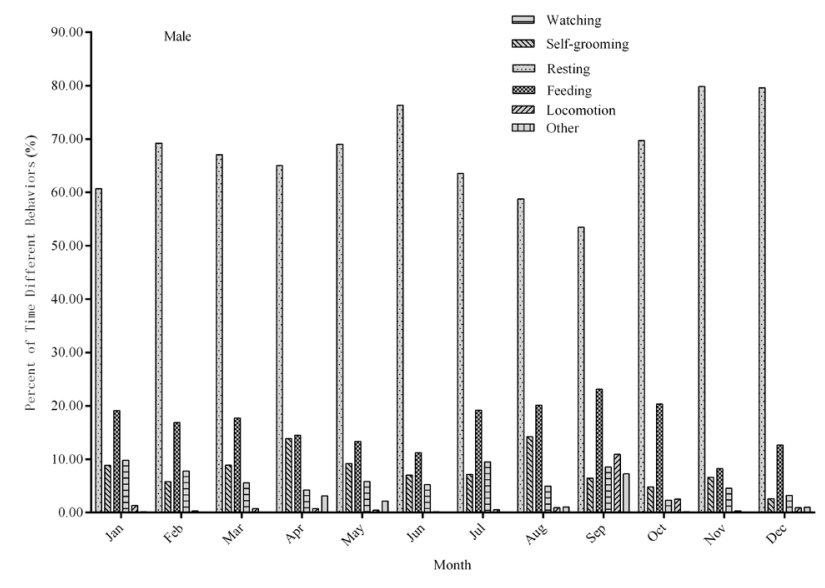

some night sessions among seasons. Resting and feeding are the most dominant behaviors. Seasons and sexes have no significant effects on total time budgets of different behaviors. But time allocated to different behaviors show notable differences in some nocturnal sessions, especially near early evening and midnight in different seasons.

Table IV. Mean percentage of different behavior lasting for \pm standard error and Wilcoxon (W) test results for male and female animals during one year $(\alpha=0.05)$.

\begin{tabular}{llll}
\hline Behavior state & Male (\%) & Female $(\%)$ & $\mathbf{Z}(\mathbf{P}$-value) \\
\hline Resting & $67.62 \pm 2.18$ & $64.52 \pm 2.64$ & $-0.785(0.433)$ \\
Feeding & $16.07 \pm 1.10$ & $17.60 \pm 0.76$ & $-0.804(0.421)$ \\
Self-grooming & $8.58 \pm 1.09$ & $8.00 \pm 0.85$ & $-0.699(0.485)$ \\
Watching & $6.38 \pm 0.78$ & $6.28 \pm 0.99$ & $-0.909(0.363)$ \\
Locomotion & $1.51 \pm 0.74$ & $1.84 \pm 0.62$ & $-0.031(0.975)$ \\
Other & $1.32 \pm 0.58$ & $0.67 \pm 0.24$ & $-1.156(0.248)$ \\
\hline
\end{tabular}

Circadian activity pattern

In this study, T. xanthipes was more active around dusk, midnight and dawn and generally showed a trimodal (even tetramodal in autumn) during the warm seasons and nocturnal activity pattern, but a bimodal activity during the cold season. Aschoff (1966) has suggested that an activity pattern with two peaks is most common in rodents. Activity patterns of $T$. xanthipes are different from that of tree squirrels which are diurnal with a bimodal activity in summer and unimodal activity in winter or autumn (e.g. Mexican fox squirrel (Sciurus nayaritensis chiricahuae) and European ground squirrel (Spermophilus citellus)) (Koprowski and Corse, 2005; Koshev and Kocheva, 2008) or only a single peak of activity during one year (such as Amazon red squirrel (Sciurus Igniventris)) (Palmer and Koprowski, 2014) and Indian giant flying squirrel (Petaurista philippensis) which is nocturnal and generally shows a bimodal activity pattern, being more active around dusk and dawn and less active at midnight autumn and has significant difference in activity during 

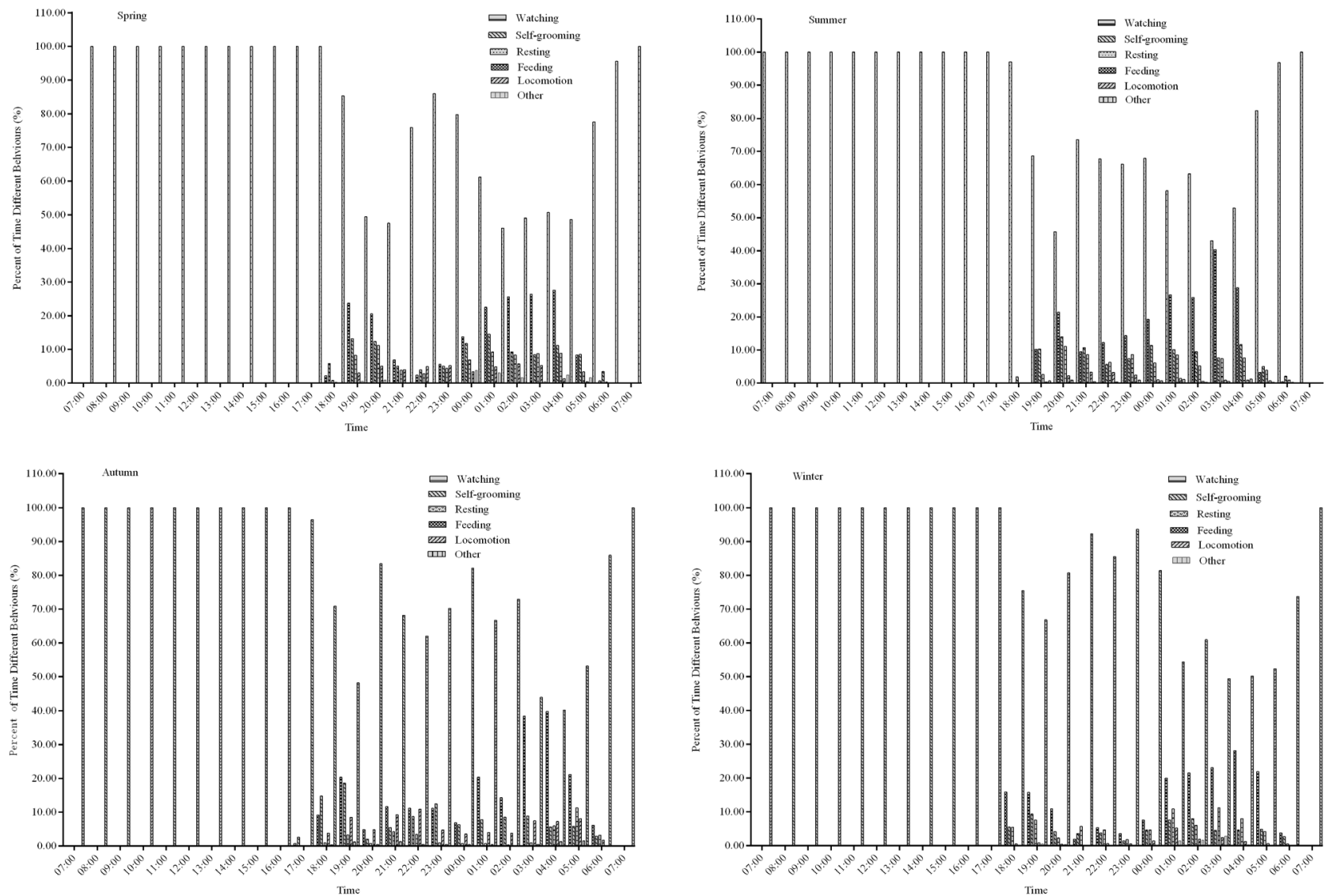

Fig. 5. Diel time budgets of different behaviors for T. xanthipes among different seasons. Data for the sexes were pooled. Spring, March to May; Summe, June to August; Autumn, September to November; Winter, December to February.

Table V. Diel variations in time budgets of different behaviors among seasons via Kruskal-Wallis $\mathrm{H}$ test. Seasonal comparisons with significant differences $(P<0.05)$ are indicated with an asterisk.

\begin{tabular}{|c|c|c|c|c|c|c|c|c|c|c|c|c|}
\hline \multirow[t]{2}{*}{ Time } & \multicolumn{2}{|c|}{ Resting } & \multicolumn{2}{|c|}{ Feeding } & \multicolumn{2}{|c|}{ Self-grooming } & \multicolumn{2}{|c|}{ Watching } & \multicolumn{2}{|c|}{ Locomotion } & \multicolumn{2}{|c|}{ Other } \\
\hline & $\chi^{2}$ & $P$ & $\chi^{2}$ & $P$ & $\chi^{2}$ & & $\chi^{2} P$ & & $\overline{\chi^{2}}$ & $P$ & $\overline{\chi^{2}}$ & $P$ \\
\hline $0700-1700$ & -- & - & - & - & - & - & - & - & - & - & - & - \\
\hline $1700-1800$ & 7.940 & $0.047 *$ & 4.333 & 0.228 & 8.946 & $0.030 *$ & 8.611 & $0.035^{*}$ & 8.946 & $0.030^{*}$ & 0.000 & 1.000 \\
\hline $1800-1900$ & 7.893 & $0.048^{*}$ & 10.28 & $0.016^{*}$ & 9.515 & $0.023^{*}$ & 13.09 & $0.004 * *$ & 12.87 & $0.005^{* *}$ & 6.529 & 0.089 \\
\hline $1900-2000$ & 6.634 & 0.085 & 5.357 & 0.147 & 1.697 & 0.638 & 8.844 & $0.031 *$ & 5.179 & 0.159 & 1.301 & 0.729 \\
\hline $2000-2100$ & 14.98 & $0.002 * *$ & 11.46 & $0.009 * *$ & 11.72 & $0.008 * *$ & 9.766 & $0.021 *$ & 8.292 & $0.040^{*}$ & 0.598 & 0.897 \\
\hline $2100-2200$ & 3.94 & 0.268 & 6.781 & 0.079 & 3.699 & 0.296 & 4.823 & 0.185 & 5.003 & 0.172 & 3.902 & 0.272 \\
\hline $2200-2300$ & 6.57 & 0.087 & 11.14 & $0.011 *$ & 3.669 & 0.300 & 6.752 & 0.080 & 7.139 & 0.068 & 9.018 & $0.029 *$ \\
\hline $2300-0000$ & 8.44 & $0.038^{*}$ & 7.252 & 0.064 & 7.320 & 0.062 & 5.466 & 0.141 & 2.857 & 0.414 & 6.277 & 0.099 \\
\hline 0000-0100 & 6.28 & 0.099 & 6.799 & 0.079 & 5.482 & 0.140 & 2.250 & 0.522 & 1.297 & 0.730 & 3.735 & 0.292 \\
\hline $0100-0200$ & 2.44 & 0.485 & 1.435 & 0.697 & 3.235 & 0.357 & 4.176 & 0.243 & 2.064 & 0.559 & 1.482 & 0.686 \\
\hline $0200-0300$ & 3.36 & 0.339 & 2.008 & 0.571 & 1.057 & 0.788 & 5.110 & 0.164 & 5.882 & 0.117 & 0.244 & 0.970 \\
\hline $0300-0400$ & 0.35 & 0.950 & 4.485 & 0.214 & 2.865 & 0.413 & 0.123 & 0.989 & 0.711 & 0.871 & 1.144 & 0.766 \\
\hline 0400-0500 & 1.000 & 0.802 & 2.472 & 0.480 & 6.429 & 0.093 & 2.738 & 0.434 & 2.385 & 0.496 & 6.082 & 0.108 \\
\hline $0500-0600$ & 5.838 & 0.120 & 8.562 & $0.036^{*}$ & 1.360 & 0.715 & 2.262 & 0.520 & 1.145 & 0.766 & 2.536 & 0.469 \\
\hline $0600-0700$ & 10.59 & $0.014 *$ & 6.486 & 0.090 & 1.596 & 0.660 & 3.510 & 0.319 & 4.670 & 0.198 & 3.031 & 0.387 \\
\hline
\end{tabular}


(Kuo and Lee, 2012; Koli and Bhatnagar, 2016). T. xanthipes is similar to Pyrenean desman (Galemys pyrenaicus) in activity patterns (Melero et al., 2014). However, we observed a shift from this bimodal activity pattern in winter, to a trimodal in spring and summer and exceptionally tetramodal pattern in autumn. Aschoff (1966) and Daan (1981) had stated that activity patterns of small mammals are shaped by intrinsic (endogenous or evolutionary trait) or extrinsic factors (temperature, photoperiod, prey availability or predation risk). The northern flying squirrel (Glaucomys sabrinus) adjusted nocturnal activity pattern between mild and harsh season. This shift probably is related to individuals' ability to adapt their behaviors to photoperiod (exactly, duration of night) and air temperature (Cotton and Parker, 2000; Melero et al., 2014). This is one of probable causes. On the other hand, the diet of T. xanthipes is relatively simple whereas most squirrels are varied in diet including nutrient-rich nuts. Requirement of energy in other squirrels could be satisfied by less alible food intake, but the animal must eat much. This may be one causal factor for more activity of T. xanthipes than other squirrels. In winter, T. xanthipes had to subsist on mature leaves which are typically less nutritious and indigestible than other plant parts (e.g. fruits, flowers, buds, young leaves) due to their high cellulose content (Garber, 1987) and spent much time to digest. To compensate for the lower energy intake rate, individuals reduced activity to conserve energy (Clutton-Brock, 1977; Dasilva, 1992). Thirdly, thinner fur and smaller body size of the flying squirrels made them to be vulnerable to cold weather in winter and so they had to curtail activity to save energy in winter. Suzuki and Ando (2017) found that Japanese flying squirrel (P. momonga) is different from most squirrels in activity patterns which was bimodal during the temperate seasons and trimodal during the cold seasons. Whether underlying genetic component was involved with the differences needs further research.

Activity peaks of $T$. xanthipes almost all occurred in early evening, midnight and early morning. That is to say, peaks in activity occurred shortly after dusk and prior to dawn. So activity patterns for the animals are related to sunrise and sunset. A different point is the peaks in spring, autumn and winter are closer to the sunset or sunrise while the peaks are 2-3 $\mathrm{h}$ from the sunset or sunrise in summer. A "midday siesta" phenomenon is always observed in diurnal squirrels and other rodents in summer, which is ascribed to high midday ambient temperature for avoiding overfeeding (Katona et al., 2002; McCarley, 1966; Loehr and Risser, 1977; Hainsworth, 1995; Vispo and Bakken, 1993) or to digest the bulky summer food (Tonkin, 1983; Wauters and Dhondt, 1987; Wauters et al., 1992) during the warmest $h$ of the day. That may be the reason why the species delay or advance activity to avoid the warmer period for abstain from energy expenditure. Therefore, the ambient temperature might play an important role in activity patterns of $T$. xanthipes. However, no significant differences in diel activity time across months were found that may be associated with the main diet being the leaves of evergreen Platycladus orientalis which can be obtained in every season. Further experiments would be necessary to test the effects of other possible factors including humidity, lunar cycle, reproduction constrains, geographical variation and predation risk on their nocturnal activity patterns.

\section{Time budgets and seasonal variation}

Although $T$. xanthipes seemed to rest more frequently in winter than other seasons, no significant differences were found in time budgets of all behaviors among seasons. The longer resting periods in winter may be related to lower quality forage (old leaves are less digestible) and reproduction (Wang et al., 1987; Wang and Wang, 1995). It was not surprising that percentage of time in feeding was not significantly different across seasons. One reason may be that this species does not hibernate in winter that they need persistent feeding to meet their energy requirement. Another explanation may be that evergreen Platycladus orientalis can provide enough food in every season.

The percentage of watching in the species remains in $5 \%-6 \%$ in each season during one year. This is consistent with previous reports that animals either allocate their time among activities or use vigilance to trade off foraging rate and predation risk while engaged in a particular activity or observe conspecifics (Joel, 1999; Quenette, 1990; Fernandez-Juricic et al., 2005; Blanchard and Fritz, 2007). Being a manner of vigilance, watching (i.e. scanning the surrounding environment) accounted for a certain proportion of activity budgets in T. xanthipes. The proportion was less than that of California ground squirrels (Spermophilus beecheyi) (the percentage of the latter reached 12.8\%) (Leger et al., 1983), much less than that of European ground squirrels (Spermophilus citellus) (the percentage of vigilance of the animals even accounted for $68.2 \%$ during gestation) (Youlatos et al., 2007), but no less than that of Indian giant flying squirrel (Petaurista philippensis) (5.71\%) (Koli and Bhatnagar, 2016). A possible explanation is that T. xanthipes and Petaurista philippensis could easily escape from predation due to performance of gliding. Many social animals have shown a decrease in vigilance with an increase in group size (Elgar, 1989; Quenette, 1990; Roberts, 1996; Bednekoff and Lima, 2005; Edwards and Waterman, 2011). This is called "group-size effect" on vigilance (Lima and Dill, 1990). It shows the animals use the costly behavior to acquire the 
foraging-vigilance trade-off. However, in the presence of conspecifics, whether T.xanthipes increase vigilance or not needs further study.

In addition, the time budgets of all behaviors in $T$. xanthipes are generally different to those of other tree squirrels. It spent less time in feeding and locomotion than Eastern gray squirrel (Sciurus carolinensis) (Erossy, 1973; Hampshire, 1985; Gurnell, 1987), Eurasian red squirrel (Sciurus vulgaris) (Wauters et al., 1992), Big Cypress fox squirrel (Sciurus niger avicennia) (Jodice and Humphrey, 1992), Mexican fox squirrel (Koprowski and Corse, 2005) and the squirrel glider (Petaurus norfolcensis) (Holland et al., 2007) and consumed much time in resting, selfgrooming than these tree squirrels. The differences in percentage of time in feeding and locomotion may be due to different diet in different squirrel species. Leaves which are main diet of T. xanthipes are generally abundant and easily obtained than nuts which are main food of other squirrel species that possibly results in reduced foraging effort to meet energy demands. Another major constraint on time budgets of feeding in the tree squirrels may be gut capacity, which results in the necessity to cease energy intake for a refractory period that permits digestion (Wauters et al., 1992). The leaves which contain more fiber are much more difficult to be digested than nuts which possibly reduce the time budget of feeding in T. xanthipes. Thus availability of food, gut capacity and gliding performance may cause the differences in time budget in feeding between T. xanthipes and other squirrel species.

Sex differences were not found in time budgets of all behaviors during one year for T. xanthipes. Although females tended to employ more time in feeding than males during one year, the difference was not significant. Further work needs to be done to investigate effects of reproduction and lactation on time budgets of behavior in females.

When comparing time budgets of different behaviors for the animals across diel $h$ among seasons, the remarkable differences were found in different time periods, with these behaviors recorded near sunset, midnight and sunrise. This may be related to photoperiod. On the other hand, during the 2-3 $\mathrm{h}$ from nine o'clock in the evening to zero o'clock in the morning, resting was dominant, other behaviors reached a lowest level. The results are similar to the Indian giant flying squirrel (Petaurista philippensis) (Kuo and Lee, 2012). Resting after a heavy meal may digest food, also avoid predators.

Overall, the main activity pattern of $T$. xanthipes in different seasons, generally being trimodal, may be associated with photoperiod, air temperature, food habits, thinner fur and body size of the animal. Peaks of activity occurred in early evening, midnight and early morning, this may be related to photoperiod and ambient temperature. The percentages of nighttime spent in each of the seven defined behaviors varied significantly in some time period in different seasons, especially near early evening and midnight. This may be ascribed to variation in photoperiod. It is concluded that ecological factors and biological characteristic are important driving force for circadian activity patterns and variation in investment of different behaviors. More detailed studies would need to be done to enhance the understanding of the effects of different eco-climatic conditions, especially the combined effects of photoperiod, temperature, relative humidity, predation pressure, etc., on activity and behavior of the species.

\section{ACKNOWLEDGEMENTS}

This work was supported by Co-Innovation Center for Qinba regions'sustainable development of Shaanxi Normal University and Shaanxi Xueqian Normal University scientific research item (2018YBKJ29). We thank $\mathrm{Mr}$ Wang Jinhong, the manager of Jin Hong Special Economic Animal Breeding Development Co. Ltd in Shangluo city, Shaanxi province, China. He provided great convenience and gave us warmness for the research project.

\section{Statement of conflict of interest}

The authors declare that they have no competing interests.

\section{REFERENCES}

Abrahamson, E.E., Moore, R.Y., 2001. Suprachiasmatic nucleus in the mouse: Retinal innervation, intrinsic organization and efferent projections. Brain. Res., 916: 172-191. https://doi.org/10.1016/S00068993(01)02890-6

Alcock, J., 2005. Choosing where to live. In: Animal behavior: an evolutionary approach (eds. J. Alcock and P. Farley), Sinauer Associates Inc, Sunderland: 249-278.

Aschoff, J., 1960. Exogenous and endogenous components in circadian rhythms. Cold Spring Harb. Symp. Quant. Biol., 25: 11-28. https://doi. org/10.1101/SQB.1960.025.01.004

Aschoff, J., 1963. Comparative physiology: diurnal rhythms. Annu. Rev. Physiol., 25: 581-600. https:// doi.org/10.1146/annurev.ph.25.030163.003053

Aschoff, J., 1966. Circadian activity pattern with two peaks. Ecology, 47: 657-662. https://doi. org/10.2307/1933949

Bednekoff, P.A. and Lima, S.L., 2005. Testing for peripheral vigilance: Do birds value what they 
see when not overtly vigilant? Anim. Behav., 69: 1165-1171. https://doi.org/10.1016/j. anbehav.2004.07.020

Blanchard, P. and Fritz, H., 2007. Induced or routine vigilance while foraging. Oikos, 116: 1603-1608. https://doi.org/10.1111/j.0030-1299.2007.15799.x

Cederlund, G., Bergstrom, R. and Sandegren, F., 1989. Winter activity patterns of females in two moose populations. Can. J. Zool., 67: 1516-1522. https:// doi.org/10.1139/z89-216

Chen, S.K., 2010. SPSS statistical analysis from entry to master, 1nd. Tsinghua University Press, Beijing, China.

Clutton-Brock, T.H., 1977. Some aspects of intraspecific variation in feeding and ranging behaviour in primates. In: Primate ecology: Studies of feeding and ranging behaviour in lemurs, monkeys and apes (ed. T.H. Clutton-Brock). Academic Press Inc, London. pp. 539-556. https://doi.org/10.1016/ B978-0-12-176850-8.50023-8

Cotton, C.L. and Parker, K.L., 2000. Winter activity patterns of northern flying squirrel in sub-boreal forests. Can. J. Zool., 78: 1896-1901. https://doi. org/10.1139/z00-137

Daan, S., 1981. Adaptive daily strategies in behavior. In: Hand book of behavioral neurobiology-biological rhythm (ed. J. Aschoff). Plenum Press, New York. pp. 275-296. https://doi.org/10.1007/978-1-46156552-9_15

Dasilva, G.L., 1992. The western black-and-white colobus as a low energy strategist: activity budgets, energy expenditure and energy intake. J. Anim. Ecol., 61: 79-91. https://doi.org/10.2307/5511

Duncan, P., 1985. Time-budgets of Camargue horses. III. Environmental influences. Behaviour, 92: 188208. https://doi.org/10.1163/156853985X00442

Edwards, S. and Waterman, J.M., 2011. Vigilance and grouping in the southern African ground squirrel (Xerus inauris). Afr. J. Ecol., 49: 286-291. https:// doi.org/10.1111/j.1365-2028.2011.01262.x

Fernández-Juricic, E., Smith, R. and Kacelnik, A., 2005. Increasing the costs of conspecific scanning in socially foraging starlings affects vigilance and foraging behaviour. Anim. Behav., 69: 73-81. https://doi.org/10.1016/j.anbehav.2004.01.019

Elgar, M.A., 1989. Predator vigilance and group size in mammals and birds: A critical review of the empirical evidence. Biol. Rev., 64: 13-33. https:// doi.org/10.1111/j.1469-185X.1989.tb00636.x

Erossy, P.J., 1973. Home range and social organization of a free ranging population of gray squirrels (Sciurus carolinensis). M.S. thesis, Bowling Green
State University, Bowling Green, Ohio.

Essner, R.L., 2007. Morphology, locomotor behaviour and microhabitat use in North American squirrels. J. Zool., 272: 101-109. https://doi.org/10.1111/ j.1469-7998.2006.00247.x

Gao, S.X. and Deng, M.L., 1983. Ecological observation of the complex-toothed squirrel (Trogopterus xanthipes) and formation of mixture of urine and feces. Special Wild Econ. Anim. Pl. Sci. Res., 3: 2829.

Garber, P.A., 1987. Foraging strategies among living primates. Annu. Rev. Anthropol., 16: 339-364. https://doi.org/10.1146/annurev. an.16.100187.002011

Gurnell, J., 1987. The natural history of squirrels. Facts on File Publications, Oxford, United Kingdom.

Hampshire, R.J., 1985. A study on the social and reproductive behaviour of captive grey squirrels (Sciurus carolinensis). PhD thesis, University of Reading, Reading, United Kingdom.

Hainsworth, F.R., 1995. Optimal body temperatures with shuttling: desert antelope ground squirrels. Anim. Behav., 49: 107-116. https://doi.org/10.1016/00033472(95)80158-8

Holland, G.J., Bennett, A.F. and Rodney, V.D.R., 2007. Time-budget and feeding behaviour of the squirrel glider (Petaurus norfolcensis) in remnant linear habitat. Wildl. Res., 34: 288-295. https://doi. org/10.1071/WR06104

Jacob, N., Vuillese, P. and Pévet, P., 1997. Photoperiod does not act on the suprachiasmatic nucleus photosensitive phase through the endogenous melatonin, in the Syrian hamster. Neurosci. Lett., 229: $117-120$. https://doi.org/10.1016/S03043940(97)00428-X

Jodice, P.G.R. and Humphrey, S.R., 1992. Activity and diet of an urban population of Big Cypress fox squirrels. J. Wildl. Manag., 56: 685-692. https:// doi.org/10.2307/3809461

Joel, S.B., 1999. Vigilance, patch use and habitat selection: Foraging under predation risk. Evol. Ecol. Res., 1: 49-71.

Johnston, C. and Smith, A.T., 2016. Trogopterus xanthipes. The IUCN red list of threatened species.

Katona, K., Váczi, O. and Altbäcker, V., 2002. Topographic distribution and daily activity of a European ground squirrel population in Bugacpuszta, Hungary. Acta Theriol.,47: 45-54. https://doi.org/10.1007/BF03193565

Klein, D.C., Moore, R.Y. and Reppert, S.M., 1991. Suprachiasmatic nucleus: the mind's clock. First edition. Oxford University Press, New York. 
Koli, V.K. and Bhatnagar, C., 2016. Seasonal variation in the activity budget of Indian giant flying squirrel (Petaurista philippensis) in tropical deciduous forest, Rajasthan, India. Folia Zool., 65: 38-45. https://doi.org/10.25225/fozo.v65.i1.a6.2016

Koshev, Y. and Kocheva, M., 2008. Daily activity pattern in free-living European ground squirrels Spermophilus citellus (Mammalia: Rodentia) from Northwestern Bulgaria. Acta Zool. Bulg. Suppl., 2: 149-154.

Kosuge, T., Yokota, M., Sugiyama, K., Yamamoto, T., Ni, M.Y. and Yan, S.C., 1985. Studies on antitumor activities and antitumor principles of Chinese herbs. I. Antitumor activities of Chinese herbs. Yakugaku zasshi. J. Pharm. Soc. Japan, 105: 791-795. https:// doi.org/10.1248/yakushi1947.105.8_791

Koprowski, J.L. and Corse, M.C. 2005. Time budgets, activity periods, and behavior of Mexican fox squirrels. J. Mammal., 86: 947-952. https://doi. org/10.1644/1545-1542(2005)86[947:ТBAPAB]2. $0 . \mathrm{CO} ; 2$

Kuo, C.C. and Lee, L.L., 2012. Home range and activity of the Indian giant flying squirrel (Petaurista philippensis) in Taiwan: influence of diet, temperature, and rainfall. Acta Theriol., 57: 269276. https://doi.org/10.1007/s13364-012-0076-y

Leger, D.W., Owings, D.H. and Coss, R.G., 1983. Behavioral ecology of time allocation in California ground squirrels (Spermophilus beecheyi): microhabitat effects. J. comp. Psychol., 97: 283. https://doi.org/10.1037/0735-7036.97.4.283

Li, S.Z., 1982. Compendium of materia medica. People's Medical Publishing House, Beijing, China.

Lima, S.L. and Dill, L.M., 1990. Behavioral decisions made under the risk of predation: A review and prospectus. Can. J. Zool., 68: 619-640. https://doi. org/10.1139/z90-092

Liu, W.H. and Li, Y.S., 2000. Research on breeding of Trogopterus xanthipes under the captive conditions. J. econ. Anim., 4: 24-28.

Liu, W.H., Ren, Z.J. and Li, Z.F., 2001. Pretiminary study on the Trogopterus xanthipes feeding with leaves of fruit-tree. Acta Agric. Boreali occidentalis Sin., 10: 22-24.

Liu, Z.S., Wang, X.M., Li, Z.G., Cui, D.Y. and Li, X.Q., 2005. Seasonal variation of diurnal activity budgets by blue sheep (Pseudois nayaur) with different age-sex classes in Helan mountain. Zool. Res., 26: 350-357.

Loehr, K.A. and Risser, A.C., 1977. Daily and seasonal activity patterns of the Belding ground squirrel in the Sierra Nevada. J. Mammal., 58: 445-448. https://doi.org/10.2307/1379353

Lv, Z. and You, J.S., 1987. Behavioral observation of Trogopterus xanthipes. Pl. Prot., 5: 51.

McCarley, H., 1966. Annual cycle, population dynamics and adaptive behavior of Citellus tridecemlineatus. J. Mammal., 47: 294-316. https:// doi.org/10.2307/1378126

Melero, Y., Aymerich, P., Santulli, G. and Gosàlbez, J., 2014. Activity and space patterns of Pyrenean desman (Galemys pyrenaicus) suggest nonaggressive and non-territorial behavior. Eur. J. Wildl. Res., 60: 707-715. https://doi.org/10.1007/ s10344-014-0838-8

Meijer, J.H. and Rietveld, W.J., 1989. Neurophysiology of the suprachiasmatic circadian pacemaker in rodents. Physiol. Rev., 69: 671-707. https://doi. org/10.1152/physrev.1989.69.3.671

Mendes, C.P. and Cândido-Jr, J.F., 2014. Behavior and foraging technique of the Ingram's squirrel Guerlinguetus ingrami (Sciuridae: Rodentia) in an Araucaria moist forest fragment. Zoologia (Curitiba), 31: 209-214. https://doi.org/10.1590/ S1984-46702014000300001

Moore, R.Y. and Lenn, N.J., 1972. A retinohypothalamic projection in the rat. J. comp. Neurol., 146: 1-14. https://doi.org/10.1002/cne.901460102

Nunes, S., Muecke, E.M., Ross, H.E., Bartholomew, P.A., and Holekamp, K.E., 2000. Food availability affects behavior but not circulating gonadal hormones in maternal Belding's ground squirrels. Physiol. Behav., 71: 447-455. https://doi. org/10.1016/S0031-9384(00)00366-8

Palmer, R.R. and Koprowski, J.L., 2014. Feeding behavior and activity patterns of Amazon red squirrels. Mammalia, 78: 303-313. https://doi. org/10.1515/mammalia-2013-0083

Panda, S., Hogenesch, J.B. and Kay, S.A., 2002. Circadian rhythms from flies to human. Nature, 417: 329-335. https://doi.org/10.1038/417329a

Pittendrigh, C.S., 1960. Circadian rhythms and the circadian organization of living systems. Cold Spring Harb. Symp. Quant. Biol., 25: 159-182. https://doi.org/10.1101/SQB.1960.025.01.015

Prendergast, B.J., Nelson, R.J. and Zucker, I., 2002. Mammalian seasonal rhythms: Behavior and neuroendocrine substrates. Horm. Brain, Behav., 2: 93-156. https://doi.org/10.1016/B978-0125321044/50021-4

Quenette, P.Y., 1990. Functions of vigilance behaviour in mammals: A review. Acta Ecol., 11: 801-818.

Reiter, R.J., 1988. The melatonin rhythm its message and its significance. Neuroendocrinol. Lett., 10: 
218.

Shi, J.B., Dunbar, R.I., Buckland, D. and Miller, D., 2003. Daytime activity budgets of feral goats (Capra hircus) on the Isle of Rum: influence of season, age, and sex. Can. J. Zool., 81: 803-815. https://doi.org/10.1139/z03-055

Smith, A.T. and Xie, Y., 2009. A guide to mammals of China. first edition. Hunan Education Press, Changsha, China.

Suzuki, K.K. and Ando, M., 2017. Seasonal changes in activity patterns of Japanese flying squirrel Pteromys momonga. Behav. Process., 143: 13-16. https://doi.org/10.1016/j.beproc.2017.08.003

Ribeiro, L.F., Conde, L.O., Guzzo, L.C. and Papalambropoulos, P.R., 2009. Behavioral patterns of Guerlinguetus ingrami (Thomas, 1901) from three natural populations in Atlantic forest fragments in Espírito Santo state, Southeastern Brazil. Natureza online, 7: 92-96.

Roberts, G., 1996. Why individual vigilance declines as group size increases. Anim. Behav., 51: 1077-1086. https://doi.org/10.1006/anbe.1996.0109

Stephan, F.K. and Zucker, I., 1972. Circadian rhythms in drinking behavior and locomotor activity of rats are eliminated by hypothalamic lesions. Proc. natl. Acad. Sci., 69: 1583-1586. https://doi.org/10.1073/ pnas.69.6.1583

Tang, X.G. and Huang, W.Q., 2008. A summary of pharmacology and clinical application of feces Trogopterus. J. Emerg. Tradit. Chin. Med., 17: 101102.

Tonkin, J.M., 1983. Activity patterns of the red squirrel (Sciurus vulgaris). Mammal. Rev., 13: 99-111. https://doi.org/10.1111/j.1365-2907.1983. tb00271.x

Turek, F.W. and Campbell, C.S., 1979. Photoperiodic regulation of neuroendocrine gonadal activity. Biol. Reprod., 20: 32-50. https://doi.org/10.1093/ biolreprod/20.1.32

Vispo, C.R. and Bakken, G.S., 1993. The influence of thermal conditions on surface activity of thirteen- lined ground squirrels. Ecology, 74: 377-389. https://doi.org/10.2307/1939300

Wang, F.L., 1985. Preliminary study on the ecology of Trogopterus xanthipes. Acta Theriol. Sin., 5: 103110.

Wang, F.L. and Wang, X.F., 1995. The complex-toothed squirrel (Trogopterus xanthipes) in China. Bull. Biol., 30: 11-13.

Wang, S., 1998. China red data book of endangered animals: Mammals. first edition. Science Press, Beijing, China.

Wang, T.Z. and Xu, W.X., 1992. Glires (Rodentla and lagomorpha) Fauna of Shaanxi Province, $1^{\text {st }}$. Shaanxi Normal University Press, Xi'an, China.

Wang, Z.C., Lv, Z. and You, J.S., 1987. Observation on the habit of Trogopterus xanthipes. Pl. Prot., 5: 51.

Wauters, L.A. and Dhondt, A.A., 1987. Activity budget and foraging behaviour of the red squirrel (Sciurus vulgaris Linnaeus, 1758) in a coniferous habitat. $Z$. Säugetierk., 52: 341-353.

Wauters, L.A., Swinnen, C. and Dhondt, A.A., 1992. Activity budget and foraging behaviour of red squirrels (Sciurus vulgaris) in coniferous and deciduous habitats. J. Zool., 227: 71-86. https://doi. org/10.1111/j.1469-7998.1992.tb04345.x

Youlatos, D., Boutsis, Y., Pantis, J.D. and Hadjicharalambous, H., 2007. Activity patterns of European ground squirrels (Spermophilus citellus) in a cultivated field in northern Greece. Mammalia, 71: 183-186. https://doi.org/10.1515/ MAMM.2007.030

Youlatos, D. and Samaras, A., 2011. Arboreal locomotor and postural behaviour of European red squirrels (Sciurus vulgaris L.) in northern Greece. J. Ethol., 29: 235-242. https://doi.org/10.1007/s10164-0100248-7

Zahler, P. and Khan, M., 2003. Evidence for dietary specialization on pine needles by the woolly flying squirrel (Eupetaurus cinereus). J. Mammal., 84: 480-486. https://doi.org/10.1644/15451542(2003)084<0480:EFDSOP $>2.0$. CO $; 2$ 